\title{
Consumers' eco-product purchase decision-making behavior from the perspective of ecological awareness
}

\author{
Zhang J.* \\ Psychologicai Health Education and Consultation Center, Xijing University, Xi'an, 710123, China \\ Received: 02/07/2020, Accepted: 18/08/2020, Available online: 22/10/2020 \\ *to whom all correspondence should be addressed: e-mail: 281230248@qq.com
}

https://doi.org/10.30955/gnj.003382

\section{Graphical abstract}

\begin{tabular}{|c|c|c|}
\hline \multirow{3}{*}{$\begin{array}{c}\text { Ecological awareness: } \\
\text { Ecological knowledge } \\
\text { Ecological emotion } \\
\text { Ecological perception }\end{array}$} & Consumer characteristics: & \multirow{3}{*}{$\begin{array}{l}\text { Eco-product purchase decision- } \\
\text { making behavior: } \\
\text { eco-product information } \\
\text { gathering behavior } \\
\text { eco-product scheme evaluation } \\
\text { behavior }\end{array}$} \\
\hline & $\begin{array}{l}\text { culture, social, personal, } \\
\text { psychological, etc. }\end{array}$ & \\
\hline & & \\
\hline
\end{tabular}

\section{Abstract}

In this study, an ecological awareness rating scale and an eco-product purchase decision-making rating scale were developed based on literature and interviews with experts. The ecological awareness variables were subdivided into three aspects: ecological knowledge, ecological emotion, and ecological perception. The eco-product purchase decision-making behavior was also divided into ecoproduct information gathering behavior and eco-product scheme evaluation behavior. According to consumer decision-making theories, an ecological awarenessecological product purchase decision-making behavior model was constructed to verify the relationships between variables. Based on regression analysis, the effects of ecological knowledge, ecological emotion, and ecological perception on the two dimensions of consumers' ecoproduct purchase decision-making behavior were discussed. It is concluded that ecological awareness has a significant positive impact on the eco-product purchase decision-making behavior, which provides a reference for the development of ecological society and the cultivation of consumers' ecological consumption habits and methods.

Keywords: Ecological awareness, eco-product, purchase decision-making behavior.

\section{Introduction}

In 2018, Chinese President Xi Jinping emphasized the need to strengthen the construction of socialist ecological civilization at the 19th National People's Congress. Studies have shown that consumers' unreasonable purchasing behaviors are influenced by their ecological awareness, environmental attitudes, individual values, and reference group behaviors. Eco-product refers to a product that is beneficial to resource conservation and environmental protection (Biswas and Roy, 2015; Guerrini et al., 2018;
Kereselidze et al., 2017; Khoo et al., 2019). In this study, ecological awareness is divided into three dimensions in order: ecological knowledge, ecological emotion, and ecological perception; the impact of ecological awareness on the decision-making behavior of purchasing ecoproducts is investigated (Ahsan et al., 2019; Daniel et al., 2020; Fatin et al., 2019; Muhammad et al., 2020).

\section{Research purpose}

This paper aims to establish a relational model of ecological awareness-eco-product purchase decision-making behavior to study the impact of ecological awareness on the decision-making behavior of purchasing eco-products. The impact variables of ecological awareness and its subdimensions on the decision-making behavior of purchasing eco-products are investigated based on previous studies. The conclusions obtained from this study will contribute to promoting the sales of ecological products, so as to protect the ecological environment.

\section{Research methods}

A variety of research methods have been employed in this study. The main methods are summarized below.

\subsection{Literature reviewing method}

The authors screened a large amount of literature and relevant literature is organized based on variables such as ecological awareness and ecological product purchase decision-making behavior. A theoretical research model is proposed based on Niccica's consumption decision model and social cognitive imbalance theory (Xie, 2014).

\subsection{Interview method}

A series of interviews were carried out with students, MBA students, adult education students, and professors of Xi'an Jiaotong University, Northwest University, Zhejiang University, Huazhong Agricultural University, and Chongqing University of Technology, as well as local residents around these universities, to understand their ecological awareness, the influencing factors of the purchase decision-making, etc., which facilitates in optimizing the experiment. 


\subsection{Experimental scenario method}

In this method, experimental scenarios were employed to investigate the effects of the three dimensions of ecological awareness on the two dimensions of ecoproduct purchase decision-making behavior by varying consumer characteristic variables.

\subsection{Questionnaire survey and statistical method}

The Likert five-point scale was adopted in the questionnaire design. The collected data were analyzed by SPSS21.0, in which the relationship between variables of the study was assessed through variance mean analysis and regression analysis.

\section{Experiment design}

\subsection{Theory}

Cognitive psychologist Thomas first proposed that stimulating can cause customer buying behavior, where a closed loop of a completed consumer decision-making process is formed (Peattie, 2010). This closed-loop consists of purchase motivation generating, consumer decision making, purchase, and feedback. In this study, based on relevant consumer decision-making processes and consumer behavior theories, the impacts of various dimensions of ecological awareness on the dimensions of eco-product purchase decision-making behavior were investigated by taking ecological awareness as an independent variable, and eco-product purchase decisionmaking behavior as a dependent variable, shown in Figure 1.

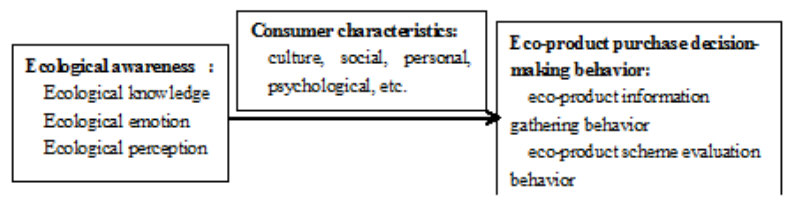

Figure 1. The model of the impacts of ecological awareness on eco-product purchase behavior

\subsection{Definitions of variables}

\subsubsection{Ecological awareness}

Ecological awareness is the understanding of the harmonious coexistence between humans and the ecological environment, between humans and society, and between society and the natural ecological environment, which includes three specific dimensions: ecological knowledge, ecological emotion, and ecological perception. Among them, ecological knowledge refers to the level of understanding of ecological products, ecological environmental protection functions, eco-products' ability to promotion of product consumption and economic development; Ecological emotion is the consumers' feelings about the environment they live in; Ecological perception is defined as the ecological consumption perceived by eco-conscious consumers can contribute to ecological environmental protection, which in line with the maximization of the interest of humanity (Zhu and Xiao, 2016). As awareness has a dynamic influence on behavior, this study is based on the role of ecological awareness in the purchase behavior of ecological products (Ali et al., 2019; Haidar et al., 2019; Héctor et al., 2020; Najatul et al., 2020).

\subsubsection{Eco-product purchase decision-making behavior}

Eco-product purchase decision-making behavior, a stage of eco-consumption behavior and the most important part of the whole eco-consumption behavior process, refers to the information gathering behavior and the scheme evaluation behavior conducted by consumers during the process of purchasing eco-products. Advocating for the purchase of ecological products is in line with the current policy of building an ecological civilization in China (Kang et al., 2018; Liu and Liu, 2010; Liu and Wang, 2017). In this regard, this study takes eco-product purchase decision-making behavior as a dependent variable to assess the influence of the three dimensions of ecological awareness on the two dimensions of eco-product purchase decision-making behavior.

\subsection{Experiment and questionnaire design}

In this study, The Likert five-point scale was employed to investigate the impacts of dimensions of ecological awareness on the dimensions of ecological product purchase decision-making behavior. Based on published literature, the following questionnaire survey was designed by taking the ecological awareness as an independent variable and the eco-product purchase decision-making behavior as a dependent variable. The questionnaire survey is shown as Table 1.

\subsection{Research hypotheses}

\subsubsection{Ecological awareness positively affects eco-product purchase decision-making behavior}

Sheth suggested that eco-conscious consumers tend to purchase products that have less impact on the environment (Sun and Jiang, 2013); Chen pointed out that ecological awareness, which governs the ecological behavior, is the basic understanding and attitude towards the ecological environment, when investigating the ecological awareness and behavioral characteristics of tourists (Chen and Yu, 2011); Wang (2013) proposed that ecological psychologists are another variables of ecological consumption behavior (Wang and Zheng, 2013). Based on mainstream opinions, in this study, it is assumed that ecological awareness has a positive influence on the decision-making behavior of eco-product purchases.

$\mathrm{H}$ : Ecological awareness positive affects eco-product purchase decision-making behavior.

\subsubsection{Ecological knowledge positively affects eco-product purchase decision-making behavior}

Peattie, Tamashiro, Li, and other researchers all agree that ecological awareness plays a positive role in ecological consumption behavior (Li, 2018). Feng proposed that that ecological knowledge has no direct effect on the ecological protection behavior of forest farmers when studying their environmental protection behavior in forest areas (Feng and Xue, 2017). Hence, we propose that ecological knowledge can enhance consumers' understanding of ecology to a certain extent and, as a result, they may pay 
more attention to the ecological environment or ecological products. In this study, it is proposed that ecological knowledge, as a dimension of ecological awareness, may positively affect the purchasing behavior of ecological products.
Ha: Ecological knowledge positively affects eco-product purchase decision-making behavior

Ha1: Ecological knowledge positively affects eco-product information gathering behavior

Ha2: Ecological knowledge positively affects eco-product scheme evaluation behavior

Table 1. Ecological awareness questionnaire survey

\begin{tabular}{|c|c|c|c|}
\hline Variable & Item & Subjects & Reference \\
\hline \multirow{4}{*}{$\begin{array}{l}\text { Ecological } \\
\text { knowledge }\end{array}$} & 1 & $\begin{array}{l}\text { Eco-products are products that are harmless or less harmful to the ecological } \\
\text { environment. }\end{array}$ & \multirow{4}{*}[1,6]{} \\
\hline & 2 & Ecological products benefit ecological environment protection. & \\
\hline & 3 & Ecological products have a positive effect on health. & \\
\hline & 4 & Biodegradable plastics contribute to ecological environmental protection. & \\
\hline \multirow{4}{*}{$\begin{array}{l}\text { Ecological } \\
\text { emotion }\end{array}$} & 1 & $\begin{array}{l}\text { When I see the living environments of animals and plants are destroyed, I will be very } \\
\text { sad. }\end{array}$ & \multirow{4}{*}[1,6,17]{} \\
\hline & 2 & $\begin{array}{l}\text { When I learn that some companies do not pay attention to ecological protection, I will be } \\
\text { very disgusted with the company's products and even stop buying their products. }\end{array}$ & \\
\hline & 3 & I feel very guilty when I don't pay attention to ecological environment protection. & \\
\hline & 4 & $\begin{array}{l}\text { I am willing to choose eco-products when eco-products and non-eco-products are all } \\
\text { available. }\end{array}$ & \\
\hline \multirow{3}{*}{$\begin{array}{l}\text { Ecological } \\
\text { perception }\end{array}$} & 1 & I believe my purchase of eco-products contributes to ecological protection. & \multirow{3}{*}[1,5,8]{} \\
\hline & 2 & I believe eco-products contribute to ecological protection. & \\
\hline & 3 & $\begin{array}{l}\text { For the interest of society, I am willing to sacrifice a small potation of personal interest to } \\
\text { purchase eco-products (Eco-products cost more). }\end{array}$ & \\
\hline \multirow{7}{*}{$\begin{array}{c}\text { Eco-product } \\
\text { purchase } \\
\text { decision-making } \\
\text { behavior }\end{array}$} & 1 & $\begin{array}{l}\text { When deciding to buy a product, I will collect some relevant information about ecological } \\
\text { products through the internet. }\end{array}$ & \multirow{7}{*}[1,6,14]{} \\
\hline & 2 & $\begin{array}{l}\text { When deciding to buy a product, I will refer to the opinions or suggestions from my } \\
\text { friends regarding eco-products. }\end{array}$ & \\
\hline & 3 & $\begin{array}{l}\text { When deciding to buy a product, I always refer to environmental information as an } \\
\text { important indicator. }\end{array}$ & \\
\hline & 4 & I prefer ecological products when looking for alternative products. & \\
\hline & 5 & $\begin{array}{l}\text { I always buy products that are environmentally friendly or less polluting and beneficial to } \\
\text { myself. }\end{array}$ & \\
\hline & 6 & $\begin{array}{l}\text { As long as a product is good for the environment, I will buy it, even if it has little benefit } \\
\text { to myself. }\end{array}$ & \\
\hline & 7 & $\begin{array}{l}\text { I will try my best to choose products produced by companies that contribute to } \\
\text { environmental protection. }\end{array}$ & \\
\hline
\end{tabular}

\subsubsection{Ecological emotion may positively affect eco-product purchase decision-making behavior}

Hines confirmed the correlation between environmental emotion and environmental behavior (Heinz and Jan, 2015). Wang (2015) proposed that environmental emotions have a greater impact on low-carbon consumption behavior than high-carbon consumption behavior, and positive environmental emotion has a greater impact on low-carbon emission behavior than negative emotion (Wang and Zhao, 2015). As most researchers believe that ecological emotions have a positive effect on ecological consumption, in this study, it is proposed that ecological emotion may positively affect the intention of consuming eco-products.

$\mathrm{Hb}$ : Ecological emotion may positively affect eco-product purchase decision-making behavior

$\mathrm{Hb} 1$ : Ecological emotion positively affects eco-product information gathering behavior
$\mathrm{Hb} 2$ : Ecological emotion positively affects eco-product scheme evaluation behavior

4.4.4. Ecological perception may positively affect ecoproduct purchase decision-making behavior

Qingping concluded that the more customers believe ecofriendly consumption behavior can bring benefits to the environment and themselves, the stronger the willingness of purchasing eco-friendly vegetables will be, and vice versa (Qing et al., 2015). Lu et al. concluded that consumers' positive perception of the functional value and emotional value of B2B products is positively correlated with the willingness of purchasing (Lu et al., 2017). Therefore, based on the literature on perceived value and perceived effectiveness studies, in this study, it is proposed that ecological perception may positively influence ecoproduct purchasing decision-making behavior.

Hc: Ecological perception positively affects eco-product purchase decision-making behavior 
Hc1: Ecological perception positively affects eco-product information gathering behavior

Hc2: Ecological perception positively affects eco-product scheme evaluation behavior

\section{Empirical study on the impact of ecological awareness on eco-product purchase decision-making behaviors}

\subsection{Questionnaire and data collection}

In this study, 400 volunteers were invited to participate in the experiment, during which the experimental variables were controlled, and questionnaire data were collected onsite. To ensure the objectivity of the data, these volunteers are senior Ph.D. and master candidates, social personnel, and MBA students. These sample data cover 5 universities in different provinces of China to ensure complexity. A total of 379 questionnaires were collected, and the questionnaire recovery rate was 94.75\%; 356 questionnaires were valid, which was $89.0 \%$ of the collected questionnaires. These valid questionnaires met the data analysis requirements of this empirical study.

5.2. Basic statistical analysis and verification of this empirical study

\subsubsection{Basic descriptive statistical analysis}

Previous studies have shown that sociodemographic variables, such as education, gender, age, and household income, affect the effectiveness of experimental results. Therefore, to exclude interference from information, in this study, consumers' characteristic variables were employed as control variables to regulate the variables that have no significant impact on eco-consumers' eco-product purchase behavior. Volunteers' statistical characteristics of this survey are shown in Table 2.

Table 2. Basic statistical data

\begin{tabular}{|c|c|c|c|c|c|}
\hline Item & Classification & Frequency & Percentage & Effective percentage & $\begin{array}{l}\text { Calculated } \\
\text { percentage }\end{array}$ \\
\hline \multirow{2}{*}{ Gender } & Male & 146 & 38.5 & 38.5 & 38.5 \\
\hline & Female & 233 & 61.5 & 61.5 & 100 \\
\hline \multirow{4}{*}{ Age } & $23-26$ & 151 & 39.8 & 39.8 & 39.8 \\
\hline & $27-30$ & 136 & 35.9 & 35.9 & 75.7 \\
\hline & $30-35$ & 73 & 19.3 & 19.3 & 95 \\
\hline & $\geq 35$ & 19 & 5 & 5 & 100 \\
\hline \multirow{2}{*}{ Marital status } & Unmarried & 246 & 65 & 65 & 65 \\
\hline & Married & 133 & 35 & 35 & 100 \\
\hline \multirow{3}{*}{ Level of education } & Master candidates & 269 & 70.9 & 70.9 & 70.9 \\
\hline & $\begin{array}{c}\text { Doctoral } \\
\text { candidates }\end{array}$ & 68 & 17.9 & 17.9 & 88.8 \\
\hline & MBA students & 42 & 11.2 & 11.2 & 100 \\
\hline \multirow{2}{*}{ Purchase plan } & Yes & 301 & 79.4 & 79.4 & 79.4 \\
\hline & No & 78 & 21.6 & 21.6 & 100 \\
\hline
\end{tabular}

As shown in Table 2, the majority of volunteers participated in this study are female, accounting for $61.5 \%$ of the overall volunteers; Most volunteers are between 25-35 years old, accounting for $75.7 \%$ of the overall volunteers; The percentage of unmarried volunteers is relatively large, accounting for $65 \%$ of the overall volunteers; In terms of education, the majority of volunteers are master students, accounting for $70.9 \%$ of the overall volunteers, which agrees with the education qualification of volunteers that we selected. Besides, $79.4 \%$ of the volunteers have specific plans for cars that they are going to purchase, which enhances the credibility of the questionnaire. In summary, the majority of volunteers who participated in this study are unmarried and well educated and they have car purchasing plans, which coincide with the current status of ecological product consumption, making this study a general representative case.

\subsubsection{Reliability analysis of the questionnaire}

In this study, each question was scored based on the Likert five-point scale. All these questions were modified on the basis of the classic scales published in the literature. Cronbach's Alpha coefficient was employed to evaluate the internal consistency of the questionnaire. When
Cronbach's Alpha coefficient is 0.7 and above, the degree of continuity and internal consistency of the questionnaire data is at an appropriate level.

\subsection{Empirical analysis}

In this study, the purpose of data collection and analysis is to verify the impact of each dimension of ecological awareness on each dimension of eco-product purchase decision-making behavior; Correlation analysis and regression analysis are the main methods used to verify the hypothesis.

\subsubsection{Pearson's correlation analysis}

Person's correlation analysis was adopted in this study to evaluate the degree of relationship between two variables. The hypothesis involves two variables: ecological awareness and eco-product purchase decision-making behavior. Ecological awareness is divided into three dimensions: ecological knowledge, ecological emotion, and ecological perception. Eco-product purchase decisionmaking behavior is divided into two dimensions: information gathering behavior and scheme evaluation behavior. The detailed correlation analysis results are listed as Table 3. 
Correlation analysis was carried out between the three dimensions of ecological awareness and the two dimensions of consumers' eco-product purchase decisionmaking behavior. As shown in Table 3, the correlations between ecological knowledge and the two dimensions of eco-product purchase decision-making behavior (information gathering behavior and scheme evaluation behavior) is significant at the 0.01 level with correlation coefficients of 0.618 and 0.590 , respectively, indicating a positive correlation between ecological awareness and eco-product purchase decision-making behavior; The correlation coefficients between ecological emotion and the two dimensions of eco-product purchase decisionmaking behavior (information gathering behavior and scheme evaluation behavior) are 0.701 and 0.688 , respectively, indicating the correlation is also significant at the 0.01 level and ecological emotion is positively correlated with eco-product purchase decision-making behavior; The correlations between ecological perception and the two dimensions of eco-product purchase decision-

Table 3. Correlation analysis results

\begin{tabular}{|c|c|c|c|c|c|c|}
\hline & & $\mathbf{X 1}$ & $\mathbf{X} 2$ & $\mathbf{X 3}$ & Y1 & Y2 \\
\hline \multirow{3}{*}{$\mathrm{x}$} & X1 Ecological knowledge & 1 & & & & \\
\hline & X2 Ecological emotion & $107 * *$ & 1 & & & \\
\hline & X3 Ecological perception & $062 * *$ & $-.313^{* *}$ & 1 & & \\
\hline \multirow{3}{*}{ Y } & Y1 eco-product information gathering behavior & $618^{* *}$ & $701 * *$ & $593 * *$ & 1 & \\
\hline & Y2 eco-product & \multirow{2}{*}{$590 * *$} & \multirow{2}{*}{$688^{* *}$} & \multirow{2}{*}{$729 * *$} & \multirow{2}{*}{$440^{* *}$} & \multirow{2}{*}{1} \\
\hline & Scheme evaluation behavior & & & & & \\
\hline
\end{tabular}

Note: ${ }^{* *}$ indicates the correlation is significant at the 0.01 level (two-tailed test)

Table 4. Regression analysis of the relationships between ecological awareness and eco-product purchase decision-making behavior

\begin{tabular}{|c|c|c|c|}
\hline \multirow{3}{*}{ Independent variable } & \multicolumn{3}{|c|}{ Dependent variable } \\
\hline & $\begin{array}{c}\text { Eco-product purchase decision-making } \\
\text { behavio }\end{array}$ & $\begin{array}{c}\text { Information gathering } \\
\text { behavior }\end{array}$ & $\begin{array}{c}\text { Program evaluation } \\
\text { behavior }\end{array}$ \\
\hline & $\begin{array}{l}\mathrm{Y} \\
\end{array}$ & Y1 & Y2 \\
\hline Constant & 872 & 931 & 1.508 \\
\hline X Ecological awareness & 631 & & \\
\hline X1 Ecological knowledge & & 812 & 899 \\
\hline X2 Ecological emotion & & 605 & 617 \\
\hline X3 Ecological perception & & 799 & 554 \\
\hline $\mathrm{R}^{2}$ & 414 & 375 & 412 \\
\hline Adjusted $\mathrm{R}^{2}$ & 401 & 362 & 398 \\
\hline DW & 1.921 & 1.862 & 1.614 \\
\hline $\mathrm{F}$ & 226.432 & 242.109 & 201.923 \\
\hline Sig & 000 & 000 & 000 \\
\hline
\end{tabular}

The regression analysis was carried out with eco-product purchase decision-making behavior as the dependent variable and ecological awareness as the independent variable. The DW statistic value is 1.921 , indicating that there is no autocorrelation in the residuals. The $F$ value is 226.432 , with a significance value of $0.000<0.01$, which indicates that the collected questionnaire data shows a good fit to the regression model and the regression result is extremely significant. The adjusted R2 of the multiple regression is 0.401 , indicating that the three dimensions of ecological awareness can interpret $40.1 \%$ of the variations of eco-product purchase decision-making behavior. Therefore, the obtained regression equation is: making behavior (information gathering behavior and scheme evaluation behavior) are significant with coefficients of 0.593 and 0.729 , respectively, implying the relationship between ecological perception and ecoproduct purchase decision-making behavior is positive.

\subsubsection{Regression analysis}

To further investigate the relationships between ecological awareness and eco-product purchase decision-making behavior, in this study, the three dimensions of ecological awareness are independent variables, and the two dimensions of eco-product purchase decision-making behavior are dependent variables. Based on the multi regression analysis results with the Enter method and the correlation analysis results obtained in the previous section, the three dimensions of ecological awareness have positive correlations between eco-product purchase decision-making behavior. The regression analysis results are shown in Table 4. 
result is extremely significant. The adjusted $R 2$ of the multiple regression is 0.362 , suggesting the three dimensions of ecological awareness can interpret $36.2 \%$ of the variations of eco-product purchase decision-making behavior. Hence, the obtained regression equation is:

Information gathering behavior $=0.931+0.812$ ecological knowledge+0.605 ecological emotion+0.799 ecological perception.

Based on this equation, the ecological knowledge has the largest impact factor $(0.812)$, followed by the ecological perception (0.799), and the ecological emotion has the smallest impact factor.

In this regard, the hypotheses $\mathrm{Ha} 1, \mathrm{Hb} 1$, and $\mathrm{Hc} 1$ are accepted: the three dimensions of ecological awareness positively affect information gathering behavior.

The regression analysis was carried out with scheme evaluation behavior as the dependent variable and the dimensions of ecological awareness as the independent variable. The obtained DW statistic value is 1.614 , meaning Table 5. Summary of Statistical Hypothesis testing Results

\begin{tabular}{cccc}
\hline Hypothesis ID & & Hypothesis content & Testing result \\
\hline $\mathrm{H}$ & Ecological awareness positive affects eco-product purchase decision-making behavior. & Accepted \\
\hline $\mathrm{Ha}$ & Ecological knowledge positively affects eco-product purchase decision-making behavior & Accepted \\
\hline $\mathrm{Ha} 1$ & Ecological knowledge positively affects eco-product information gathering behavior & Accepted \\
\hline $\mathrm{Ha} 2$ & Ecological knowledge positively affects eco-product scheme evaluation behavior & Accepted \\
\hline $\mathrm{Hb}$ & Ecological emotion may positively affect eco-product purchase decision-making behavior & Accepted \\
\hline $\mathrm{Hb} 1$ & Ecological emotion positively affects eco-product information gathering behavior & Accepted \\
\hline $\mathrm{Hb} 2$ & Ecological emotion positively affects eco-product scheme evaluation behavior & Accepted \\
\hline $\mathrm{Hc}$ & Ecological perception positively affects eco-product purchase decision-making behavior & Accepted \\
\hline $\mathrm{Hc} 1$ & Ecological perception positively affects eco-product information gathering behavior & Accepted \\
\hline $\mathrm{Hc} 2$ & Ecological perception positively affects eco-product scheme evaluation behavior & Accepted \\
\hline
\end{tabular}

\subsection{Summary of empirical study}

The empirical study of this study consists of two parts: Part 1 is a descriptive statistic of the collected samples; Part 2 is the testing of the relevant hypotheses with regression analysis. The testing results are summarized as Table 5 .

\section{Summary and discussion}

\subsection{Summary}

Consumers' characteristics and the changes in the external environment promote the trend of the behavior of choosing eco-products. The majority of the previous studies focus on the influence of external factors, such as price, income level, and personal preference, on consumer behavior, and only a small portion of studies cover the influence of internal factors (values, awareness).

In this study, with a background of ecological awareness, through the analysis of published literature and the using of SPSS21.0 data analysis software, the ecological awareness is divided into three dimensions based on an increasing trend: ecological knowledge, ecological emotion, and ecological perception; the eco-product purchasing decision behavior is divided into two dimensions: eco-product information gathering behavior and eco-product scheme evaluation behavior. Next, the correlation analysis was employed to study the relationship that there is no autocorrelation in the residuals; the $F$ value is 201.923, with a significance value of $0.000<0.01$, suggesting the collected questionnaire data shows a good fit to the regression model and the regression result is extremely significant. The adjusted R2 of the multiple regression is 0.398 , implying the three dimensions of ecological awareness can interpret $39.8 \%$ of the variation of the eco-product purchase decision-making behavior. Therefore, the obtained regression equation is:

Information gathering behavior $=1.508+0.899$

ecological knowledge +0.617 ecological emotion

+0.554 ecological perception.

According to this equation, the ecological knowledge has the largest impact factor (0.899), followed by the ecological emotion (0.617), and the ecological emotion has the smallest impact factor (0.554).

In this regard, the hypotheses $\mathrm{Hb} 1, \mathrm{Hb} 2$, and $\mathrm{Hc} 2$ are accepted: the dimensions of ecological awareness positively affect the scheme evaluation behavior. 
behavior as they believe that their shopping behaviors will have a positive effect on environmental protection. The conclusions obtained from this study provide theoretical support for the construction of ecological society and the cultivation of consumers' ecological consumption habits and routines. Policymakers can develop relevant measures from the aspects of government, consumers, enterprises, and media to promote the construction of ecological civilization, contributing to the developing of a beautiful China.

\section{References}

Ahsan M., Wang H. and Muhammad T.S. (2019), Nano-technology development for in-situ remediation of heavy metal (loid)s contaminated soil, Environment \& Ecosystem Science, 3(2), 09-11.

Ali R., Hossein H., Seyedeh B.F.M., Sara H. and Nima J. (2019), Assessment of heavy metals contamination in surface soils in Meiduk copper mine area, Se Iran, Earth Sciences Malaysia, 3(2), 1-8, DOI: 10.26480/esmy.02.2019.01.08.

Biswas A. and Roy M. (2015), Green products: An exploratory study on the consumer behaviour in emerging economies of the East, Journal of Cleaner Production, 87, 463-468.

Chen L.L. and Yu W.M. (2011), Development analysis of heritage tourism in Ji'an city, Jilin Province based on SWOT model. The Population of China, Resources and Environment, (S2), 250254.

Daniel A., Eyasu E. and Ota H.O. (2020), Flood risk zone mapping using rational model in a highly weathered Nitisols of Abakaliki Local Government Area, South-eastern Nigeria, Geology, Ecology, and Landscapes, 4(2), 131-139.

Fatin M.A., Nur Shuhada T., Rozilawati S. and Che Nurul Aini C.A. (2019), Effects of different chicken manure rates of on early growth of fig (Ficus Carica), Environmental Contaminants Reviews, 2(1), 19-22.

Feng X. and Xue Y.J. (2017), An empirical study on the influence of ecological knowledge on the ecological protection behavior of forest farmers-The intermediate function of ecological emotion and sense of responsibility, Resource Development and Market, (3), 284-288+294.

Guerrini G., Landi E., Peiffer K., et al. (2018), Dry grinding of gears for sustainable automotive transmission production, Journal of Cleaner Production, 176, 76-88.

Haidar S.A. (2019), Contribution to the paleontology, stratigraphy and paleo-biogeography of some diagnostic Pakistanian Paleogene foraminifer in the Middle East, Earth Sciences Pakistan, 29-34.

Héctor L.V.Q., Mark T. and Pablo A.G.C. (2020), Water scarcity or drought? The cause and solution for the lack of water in Laguna De Aculeo. Water Conservation and Management, 4(1), 42-45.

Heinz W. and Jan K. (2015), Determinants of pro-environmental consumption: The role of reference groups and routine behavior, Ecological Economics, 69(15), 166-176.

Kang L., Du H.L., Du X., et al. (2018), Study on dye wastewater treatment of tunable conductivity solid-waste-based composite cementitious material catalyst, Desalination and Water Treatment, 125, 296-301.

Kereselidze D., Matchavariani L., Trapaidze V., et al. (2017), Assessment of the riverside vulnerability, Journal of Environmental Biology, 38(5SI), 1025-1031.
Khoo S.C., Phang X.Y., Ng C.M., et al. (2019), Recent technologies for treatment and recycling of used disposable baby- diapers, Process Safety and Environmental Protection, 123(B), 116-129.

Li G.Z. (2018), The provincial and regional differences of carbon emission of urban residents' living energy and its influencing factors, Journal of Beijing Jiaotong University (Social Science Edition), (03), 32-40.

Liu H. and Liu Z. (2010), Recycling utilization patterns of coal mining waste in china. Resources Conservation and Recycling, 54(12), 1331-1340.

Liu W.X. and Wang X.D. (2017), Research on the consistency of ecological consumption consciousness and behavior of rural residents-Based on the investigation of ecological civilization pilot demonstration area in Jiangxi Province, Agricultural Economic Problems, (9), 78-83.

Lu H.L., Wei Y. and Zhang Y. (2017), Consumer perceived value and B2B component brand buying intentions-The moderating effect of objective knowledge level, Journal of Guizhou University of Finance and Economics, (05), 10-19.

Muhammad N.A.K., Aimrun W., Ahmad F.A. and Abdul Rashid M.S. (2020), Effect of variable rate application on rice leaves burn and chlorosis in system of rice intensification, Malaysian Journal of Sustainable Agriculture, 4(2), 66-70.

Najatul S.A., Mohd A.N., Normawaty M.N. and Zaima Azira Z.A. (2020), Diversity of cultivable bacteria by strategic enrichment isolated from farmed edible red seaweed, Gracilaria Sp. Journal Clean WAS, 4(1), 17-20.

Participated in the planning project of philosophy and social sciences of Zhejiang province "Study on the influence of ecological consciousness on ecological consumption behavior of urban residents in Zhejiang province" (16NDJC229YB).

Peattie K. (2010), Green consumption: Behavior and norms, Annual Review of Environment and Resources, 35(1), 195.

Qing P., Zhang Y. and Tu M. (2015), An experimental study on the influence of brand crisis on negative information dissemination of consumers, China's Rural Economy, (06), 63-73.

Sun Y. and Jiang L. (2013), Study on the influence of psychological factors on energy consumption behavior of urban residents, Consumer Economy, 5, 14-18.

Wang J.M. and Zhao Q.F. (2015), Statistical test of influence of Taoist values on consumer recycling behavior, Statistics and Decision, (18), 119-123.

Wang J.M. and Zheng R.R. (2013), The influence mechanism of psychological consciousness factors on ecological civilization behavior of consumers, Journal of Management, (7), 10271035.

Xie J.M. (2014), Study on green consumption consciousness and behavior pattern of college students in Beijing. Capital University of Economics and Business.

Zhu J.R. and Xiao X.J. (2016), A review on the influence of ecological consciousness on ecological consumption intention and ecological consumption behavior, Management and Administration, (3), 68-73. 